\title{
Reclassification of Halomonas caseinilytica Wu et al. 2008 as a later synonym of Halomonas sinaiensis-Comments on the proposal by Hwang et al., Antonie van Leeuwenhoek 109:1345-1352, 2016
}

\author{
Aharon Oren \\ Received: 20 September 2016/ Accepted: 25 September 2016/Published online: 30 September 2016 \\ (C) Springer International Publishing Switzerland 2016
}

\begin{abstract}
Hwang et al. (Antonie van Leeuwenhoek 109:1345-1352, 2016) proposed the reclassification of Halomonas caseinilytica (Wu et al. 2008) as a later synonym of Halomonas sinaiensis, based on the publication of the latter name in 2007 by Romano et al. However, the name $H$. sinaiensis was validly published only in 2011. Therefore the proposal by Hwang et al. is not appropriate; instead, the name $H$. sinaiensis can be proposed as a later synonym of $H$. casinilytica.
\end{abstract}

keywords Halomonas $\cdot$ Synonym $\cdot$ Valid publication $\cdot$ Emendation

In a paper recently published in Antonie van Leeuwenhoek, Hwang et al. (2016) proposed the reclassification of Halomonas caseinilytica (Wu et al. 2008) as a later synonym of Halomonas sinaiensis. This proposal was based on the publication of the name $H$. sinaiensis by Romano et al. (2007). Hwang et al. also presented an emended description of $H$. sinaiensis.

\footnotetext{
A. Oren $(\square)$

The Institute of Life Sciences, The Hebrew University of Jerusalem, The Edmond J. Safra Campus,

91904 Jerusalem, Israel

e-mail: aharon.oren@mail.huji.ac.il
}

$H$. caseinilytica cannot be proposed as a later synonym of $H$. sinaiensis as the name $H$. caseinilytica has priority: it was validly published in 2008 , while the name $H$. sinaiensis, effectively published by Romano et al. (2007), was validated only in Validation List 141, published in 2011 (Euzéby 2011). A proposal to reclassify $H$. sinaiensis as a later heterotypic synonym of $H$. caseinilytica would have been appropriate, accompanied by an emended description of $H$. caseinilytica.

\section{References}

Euzéby J (2011) List of new names and new combinations previously effectively, but not validly, published-Validation List No. 141. Int J Syst Evol Microbiol 61:2025-2026

Hwang CY, Lee I, Yoon SJ, Lee YM, Lee WS, Lee HK (2016) Reclassification of Halomonas caseinilytica Wu et al 2008 as a later synonym of Halomonas sinaiensis Romano et al. 2007, end emendation of the species description. Antonie van Leeuwenhoek 109:1345-1352

Romano I, Lama L, Orlando P, Nicolaus B, Giordano A, Gambacorta A (2007) Halomonas sinaiensis sp. nov., a novel halophilic bacterium isolated from a salt lake inside Ras Muhammad Park, Egypt. Extremophiles 11:789-796

Wu YH, Xu XW, Huo YY, Zhou P, Zhu XF, Zhang HB, Wu M (2008) Halomonas caseinilytica sp. nov., a halophilic bacterium isolated from a saline lake on the Qinghai-Tibet Plateau, China. Int J Syst Evol Microbiol 58:1259-1262 